\title{
The precision of predicting the time of onset of parturition in the bitch using the level of progesterone in plasma during the preparturient period
}

\author{
K G M De Cramer ${ }^{1}$ and J O Nöthling ${ }^{1}$ \\ ${ }^{1}$ *Corresponding author. Department of Production Animals, Faculty of Veterinary Science, University of \\ Pretoria, South Africa, kdcramer@mweb.co.za \\ ${ }^{1}$ Department of Production Animals, Faculty of Veterinary Science, University of Pretoria, South Africa, \\ Johan.Nothling@up.ac.za \\ *Current address of corresponding author. Tel +27 0116603110. P.O. Box 704, Rant en dal, 1751, Mogale city, \\ South Africa. Email address: kdcramer@mweb.co.za. Rant en Dal Animal Hospital, 51 Cecil Knight Street, \\ Mogale City, Gauteng, South Africa
}

\section{Highlights}

- The plasma level of progesterone to predict the time of onset of parturition was evaluated in 25 preparturient bitches.

- Levels below $8.7 \mathrm{nmoL} / \mathrm{L}$ indicate that there is a $99 \%$ probability of parturition within $48 \mathrm{~h}$.

- Levels below $3.18 \mathrm{nmoL} / \mathrm{L}$ indicate there is a $100 \%$ probability of parturition within $24 \mathrm{~h}$.

\begin{abstract}
Precise prediction of the time of onset of parturition in the bitch is of clinical importance. Many parturition management cases in clinical practice are presented in the last two weeks of pregnancy without a reliable estimate of the parturition date. The aim of this study was to assess the value of a single progesterone level in the blood plasma from a preparturient bitch to predict the time of onset of parturition. The temporal relationship between the decrease in the plasma progesterone levels and the time of cervical dilatation (TCD)—which correlates to
\end{abstract}


the onset of stage 1 of parturition-was evaluated in 25 bitches in the preparturient period. Among bitches destined to reach TCD within $12 \mathrm{~h}$ there is a $2 \%$ probability of having a plasma progesterone level of $15.8 \mathrm{nmol} / \mathrm{L}$ or above and a $6 \%$ probability of having a level of $8.7 \mathrm{nmol} / \mathrm{L}$ or above. Conversely, if the level is below $8.7 \mathrm{nmol} / \mathrm{L}$ there is a $99 \%$ probability of reaching TCD within $48 \mathrm{~h}$ and if the level is below $3.18 \mathrm{nmol} / \mathrm{L}$ there is a $100 \%$ probability of reaching TCD within $24 \mathrm{~h}$. These results allow the veterinary obstetrician to make prompt decisions in the management of parturition.

Keywords: Progesterone; parturition; bitch

\section{Introduction}

Predicting the time of onset of spontaneous parturition in the bitch in late gestation is clinically important. The time spent observing parturition may be drastically shortened if one can accurately predict a particular interval wherein the bitch is either very likely or very unlikely to enter spontaneous parturition.

The onset of parturition (the first stage of parturition) is characterized by the dilatation of the cervix which also signals readiness for caesarean section (CS) [1]. Because the behavioral signs associated with early stage 1 of parturition may be variable [2], cervical dilatation offers a reliable and objective indicator of onset of the first stage of parturition. Following the first stage are the second and third stages, during which the fetuses and the placentas are delivered.

The majority of bitches presented in late gestation for parturition management are ones for which only mating dates are available. Mating dates are of no help in predicting parturition dates [3-6]. In late pregnancy it was concluded that the biparietal diameter was most accurate in predicting gestational age and that the crown rump length may be difficult to measure 
because of fetal flexion and fetal lengths that exceed the size of the ultrasound image [7-9]. A study involving English bulldogs suggested that caesarean sections (CSs) can be scheduled safely when the fetal biparietal diameter has reached a value of $29.5 \mathrm{~mm}$ or above [10]. Further studies are required to establish whether it is routinely safe to time CS based on methods involving gestational age estimation in dogs by ultrasonographic assessment of fetal biometric measurements.

Progesterone appears thermogenic in the dog [11] but the effect may be variable [12-17] and some bitches may not demonstrate a detectable preparturient decrease in rectal temperature even when monitored three times daily [18]. It may therefore be concluded that the preparturient temperature decrease can give important clues but that it is not accurate or reliable enough to use as sole predictor of the time of parturition or indicating fetal maturity and safety for intervention by CS.

The level of progesterone in blood plasma or serum (PL) decreases prior to parturition [1921]. The usefulness of PL in predicting the TCD requires further investigation.

It is safe to perform a CS once the cervix has dilated [1]. The time of onset of spontaneous cervical dilatation (TCD), corresponds to the time of onset of the first stage of spontaneous parturition and therefore it would be helpful if there were a method to predict TCD in bitches that are in the preparturient period.

The aim of this study was to assess the value of a single PL from a preparturient bitch to predict TCD.

\section{Materials and Methods}

The protocol was approved by the Animal Ethics Committee of the Faculty of Veterinary Science, University of Pretoria, (Onderstepoort, South Africa) (protocol number V010/14). 


\subsection{Bitches}

The experimental animals were all English bulldog and Boerboel bitches presented to a private veterinary clinic for routine estrus observation, artificial insemination and elective CS. The decision to plan an elective CS was based on breed in the case of English bulldogs and on the history of previous dystocia, puppy losses and CS in Boerboels. All bitches weighed more than $20 \mathrm{~kg}$. All owners declined an attempt to allow the bitches to undergo spontaneous unassisted parturition. The current study included 28 bitches (12 English bulldog and 16 Boerboel). All bitches used in the current study were well habituated, used to travelling, showing and residing at the obstetric clinic for purposes of artificial insemination and management of parturition. Bitches that were combative or resisted the minimal restraint required to collect blood were not included in the study. All experimental animals were housed and fed commercial dry pellets twice daily with ad-lib water.

\subsection{Collection of specimens and data}

During pro-estrus and estrus, vaginal speculum examinations and vaginal smears were made once daily to establish the first day of cytological diestrum (D0), using the criteria set out by Holst and Phemister (1974). An ultrasound examination was performed between D26 (26 d after the onset of D0) and D35 to confirm pregnancy and identify bitches carrying a singleton. In the preparturient period, starting at D54, each bitch was admitted for parturition management and if a small litter was suspected, a radiograph was taken to confirm litter size and exclude singleton pregnancies from the study. On the day of admission, a central venous catheter (18 gauge, $20 \mathrm{~cm}$ in length, Catalogue Number 04218, Arrow International, Pennsylvania, USA) was instilled in their jugular vein and heparinized blood was collected every $6 \mathrm{~h}$ at 6:00, 12:00, 18:00 and 24:00, with the last collection at TCD. Immediately before each blood collection, a Perspex tubular speculum (22 mm outer diameter, $17 \mathrm{~mm}$ inner diameter, length $280 \mathrm{~mm}$ ) was passed into the vagina to determine whether the cervix had dilated. A cold light source was used to illuminate the speculum. In cases where mucus in the anterior vagina obscured viewing the cervix, the mucus was suctioned using a Perspex 
bovine insemination pipette and a $20 \mathrm{ml}$ syringe. In 16 bitches that showed signs of first-stage labor a vaginal speculum examination was performed less than 5 hours after the last scheduled examination and revealed that cervical dilatation had begun. In these 16 bitches, the blood sample at TCD was collected more than one hour before the next scheduled time. Once at TCD, a bitch was considered ready for immediate CS. TCD identified the day and time of onset of spontaneous parturition.

The blood was immediately transferred to a 10-ml green-stoppered heparinized glass vial (BD Vacutainer ${ }^{\circledR}(170$ IU lithium heparin), BD Plymouth, UK) and was centrifuged within $30 \mathrm{~min}$ after collection, following which it was transferred to $1.8 \mathrm{ml}$ cryo vials (Catalogue number 750273 , PlastPro Scientific, Edenvale South Africa), labelled and frozen at $-20{ }^{\circ} \mathrm{C}$ until analyzed.

The levels of progesterone and cortisol were determined in each plasma sample, using the Coat-A-Count ${ }^{\circledR}$ radioimmunoassay (Siemens Health Care Diagnostics Inc. Los Angeles, CA 90045 USA) for each hormone. This assay has been validated for dog plasma [22] and used to determine the progesterone level (PL or PLs for progesterone levels) in the serum or plasma of bitches for decades [23-28] and for cortisol assays [29-31].

All determinations of PL and cortisol were done in duplicate (two replicates simultaneously done in the same assay). The intra-assay coefficient of variation was determined for the PLs of the two replicates of each sample. The levels of cortisol of 19 plasma samples were each determined in two assays and the mean level of each sample in each assay used to determine the interassay coefficient of variation.

Six plasma samples from peri-estrous bitches - two of which had PLs between $2 \mathrm{nmol} / \mathrm{L}$ and $4 \mathrm{nmol} / \mathrm{L}$, two had PLs between $13 \mathrm{nmol} / \mathrm{L}$ and $14 \mathrm{nmol} / \mathrm{L}$ and two had PLs between 
$22 \mathrm{nmol} / \mathrm{L}$ and $23 \mathrm{nmol} / \mathrm{L}$ - were each analyzed in six or seven different assays and the interassay coefficient of variation calculated.

\subsection{Data analysis}

Data of bitches carrying more than one fetus and on which a CS was performed once cervical dilatation was first noticed were used for analysis.

2.3.1. General investigation of the pattern of change, and variability of progesterone levels during the preparturient period

A set of line graphs were compiled showing the PL at each of the six-hourly measurements prior to TCD in each bitch and the pattern of change in individual bitches and the variability among bitches visually appraised.

We used a mixed-effect regression with progesterone level as response variable, time before cervical dilation and breed as covariates and bitch as random effect. The interaction between the covariates was also included in the model. This analysis was done on 272 progesterone levels, excluding the 25 at the time of onset of cervical dilatation in each bitch, because these 25 were only measured after vaginal speculum examination had confirmed the onset of cervical dilatation.

\subsubsection{Selecting the progesterone level that would best predict the time to cervical dilatation}

\subsubsection{Identifying possible cross points}

A scatterplot of PL against time was generated, where time represents the time until cervical dilatation was first noted (TCD), which was denoted time zero. Progesterone level was plotted on the y-axis, with PL increasing with height on the axis. Time was plotted on the xaxis, with Time zero on its right extreme and the time most distantly preceding Time zero on its left. Vertical lines on the graph are referred to as time lines and horizontal lines as PL 
lines. The point where a time line and a PL line cross we termed a cross point. All PLs from each of the 25 bitches were plotted on the scatterplot.

Ignoring the PLs at Time zero — by which time the cervix had started to dilate - the scatterplot (Figure 2) was visually inspected and subjectively appraised for a pattern of change of PL over time. Given the downward trend in PL as time zero approached, a search for possible cross points was done.

Either of two criteria defined useful cross points. The first was that the top right quadrant (the zone above or on the PL line through the cross point and to the right of or on the time line through it) should have as few as possible of the PLs on the scatterplot. (This is so because bitches with PLs in the top right quadrant will undergo cervical dilatation sooner than suggested by their PLs at the time, possibly with unexpected and undesirable obstetric consequences.) The second criterion was that the bottom left quadrant should have as few as possible of the PLs on the scatterplot. (In the clinical setting bitches with PLs in the bottom left quadrant would not undergo cervical dilatation when expected according to their PLs, and they would require prolonged observation with follow-up obstetric examination.)

With the above criteria in mind, the scatterplot was inspected at clinically important time lines to identify that PL line at each that would either have the top right quadrant or the bottom left quadrant or both sparsely populated or without PLs.

\subsubsection{Time lines that were considered}

The clinically important time lines were 12, 24, 48 and $96 \mathrm{~h}$ before TCD.

Given a particular PL line and the general decline in PLs as TCD approaches, time lines closer to TCD are more likely to identify optimal cross points of which the top right quadrant is devoid of or sparsely populated with PLs than time lines preceding TCD by longer intervals. In the clinical setting, it would be unlikely to find a bitch with a PL above or on the 
PL line through such an optimal cross point that would reach TCD during a period shorter by the one signified by the time line through it. The 12-hours and 24-hours time lines were investigated with such benefit in mind.

Given a particular PL line, the general decline in PLs as TCD approaches suggests that time lines further ahead of TCD (closer to $96 \mathrm{~h}$ before TCD) are more likely to identify optimal cross points of which the bottom left quadrants are devoid of or sparsely populated with PLs. Such cross points will have the value of allowing clinicians to suitably schedule observation and follow-up examination of the preparturient bitch. The 96-hours, 72-hours and 48-hours time lines were investigated with such benefit in mind.

Time lines closer to TCD may also identify cross points with low PL lines of which the bottom left quadrant is sparsely populated or free of PLs. Such cross points may allow clinicians to identify bitches in which TCD is due soon. If the time line through the cross point is sufficiently close to TCD it may allow the clinician to safely perform a preparturient CS or to schedule it to follow shortly. The 12-hours and 24-hours time lines were selected for investigation with such benefit in mind.

\subsubsection{Priorities by which to search for the best cross point} Various parameters were considered as means of comparing candidate cross points. These parameters were the sensitivity (SE), specificity (SP), false negative fraction (FNF), false positive fraction (FPF), positive predictive value (PPV) and negative predictive value (NPV) [32]. Those parameters that would be most suitable to quantitatively characterize a cross point were short-listed and used to compare cross points. Referring to Figure 2, the following symbols were used to facilitate description of a cross point: $T_{R}=$ number of PLs in the top right quadrant, $B_{R}=$ number of PLs in the bottom right quadrant, $T_{L}=$ number of PLs in the top left quadrant and $\mathrm{B}_{\mathrm{L}}=$ number of PLs in the bottom left quadrant. 
2.3.2.4. Parameters pertaining to the top right quadrant FNF $=100\left(T_{R} /\left(T_{R}+B_{R}\right)\right)$. The fewer PLs in the top right quadrant relative to the number in the bottom right quadrant the lower the FNF will be. A low FNF is preferred.

$\mathrm{SE}=100\left(\mathrm{~B}_{\mathrm{R}} /\left(\mathrm{T}_{\mathrm{R}}+\mathrm{B}_{\mathrm{R}}\right)\right)$. The fewer PLs in the top right quadrant relative to the number in the bottom right quadrant the higher the SE will be. A high SE is preferred. There is a fixed relationship between FNF and SE because SE $=100-$ FNF. SE may therefore be derived from the FNF. We only used the FNF as it is intuitively aligned to the requirement for a suitable cross point (a low FNF indicates that a low proportion of PLs to the right of a time line fall above the PL line).

NPV $=100\left(T_{L} /\left(T_{L}+T_{R}\right)\right)$. The more PLs in the top left quadrant relative to the number in the top right quadrant the higher the NPV will be. A high NPV is preferred. From the general pattern of decline in PL as TCD approaches follows that more PLs should be expected in the top left quadrant of a cross point if bitches are included that are still further away from TCD than those reflected in Figure 2. The NPV therefore depends on the time horizon prior to TCD that is being considered. We therefore excluded NPV from further analysis.

From the above follows that the only parameter pertaining to the top right quadrant that we considered was the FNF.

2.3.2.5. Parameters pertaining to the bottom left quadrant $\mathrm{FPF}=100\left(\mathrm{~B}_{\mathrm{L}} /\left(\mathrm{B}_{\mathrm{L}}+\mathrm{T}_{\mathrm{L}}\right)\right)$. The fewer PLs in the bottom left quadrant relative to the number in the top left quadrant, the lower the FPF will be. A low FPF is preferred. From the general pattern of decline in PL as TCD approaches follows that more PLs should be expected in the top left quadrant of a cross point relative to the bottom left quadrant if bitches are included that are still further away from TCD than those reflected in Figure 2. The FPF therefore 
depends on the time horizon prior to TCD that is being considered. We therefore excluded FPF from further analysis.

$\mathrm{SP}=100\left(\mathrm{~T}_{\mathrm{L}} /\left(\mathrm{T}_{\mathrm{L}}+\mathrm{B}_{\mathrm{L}}\right)\right)$. The fewer PLs in the bottom left quadrant relative to the number in the top left quadrant, the higher the SP will be. A high SP is preferred. There is a fixed relationship between FPF and SP because SP $=100-$ FPF and SP was therefore also excluded from further analysis.

PPV $=100\left(B_{R} /\left(B_{R}+B_{L}\right)\right)$. The fewer PLs in the bottom left quadrant relative to the number in the bottom right quadrant, the higher the PPV will be. A high PPV is preferred.

The only parameter pertaining to the bottom left quadrant that we considered was the PPV.

Fisher's exact test was used to compare English bulldogs and Boerboels with respect to the cross points reflected in Tables 1 and 2.

\subsubsection{Performance of selected cross points}

Once the cross points associated with low FNFs and high PPVs were identified, we determined how well they characterize the 25 bitches in the study.

All analyses were done with STATA version 14 (StataCorp, 4905 Lakeway Drive, College Station, Texas 77845 USA) or with Excel.

\section{Results}

One English bulldog and two Boerboels were excluded because they had litters of one, leaving 11 English bulldogs with litters of 4 to 10 puppies (mean 6.9, SD 2.08) and 14 Boerboels with litters of 8 to 13 puppies (mean 10.07, SD 1.90) in the study.

No pattern in either the level of cortisol in the blood plasma or the change thereof over time occurred that was sufficiently consistent among bitches to warrant further appraisal of 
cortisol as a predictor of TCD. No cortisol levels other than those of the few hours preceding cervical dilatation (see Section 3.2 3.2.1 are shown.

\subsection{Precision of the progesterone assay}

The standard curve for the concentration of progesterone ranged from zero to $127.2 \mathrm{nmol} / \mathrm{L}$. The intra-assay coefficients of variation of progesterone in plasma samples from preparturient bitches with mean PLs below $2 \mathrm{nmol} / \mathrm{L}$, between $5.5 \mathrm{nmol} / \mathrm{L}$ and $6.5 \mathrm{nmol} / / \mathrm{L}$, between $16 \mathrm{nmol} / \mathrm{L}$ and $16.9 \mathrm{nmol} / \mathrm{L}$ and between $30 \mathrm{nmol} / \mathrm{L}$ and $38.7 \mathrm{nmol} / \mathrm{L}$ were respectively $9.21 \%(\mathrm{n}=20), 3.56 \%(\mathrm{n}=12), 5.83 \%(\mathrm{n}=16)$ and $2.96 \%(\mathrm{n}=16)$.

The mean interassay coefficient of variation was $12.45 \%$ for the two plasma samples with PLs of $2 \mathrm{nmol} / \mathrm{L}$ and $4 \mathrm{nmol} / \mathrm{L}, 7.21 \%$ for the two tubes with PLs of $13 \mathrm{nmol} / \mathrm{L}$ and $14 \mathrm{nmol} / \mathrm{L}$ and $5.69 \%$ for the two tubes with PLs of $22 \mathrm{nmol} / \mathrm{L}$ and $23 \mathrm{nmol} / \mathrm{L}$.

\subsection{Progesterone as preparturient predictor of TCD}

\subsubsection{General pattern of change of PL during the preparturient period}

Figure 1 shows the change in PL over time during the last few days before TCD in 25 bitches. Generally, there was a decline in PL that started $48 \mathrm{~h}$ or less prior to TCD. Both, the pattern of decline and the levels of progesterone varied substantially among bitches. In one bitch (Amie) PL increased from $2.7 \mathrm{nmol} / \mathrm{L}$ three hours before TCD to $10.2 \mathrm{nmol} / \mathrm{L}$ at TCD. In another (Zandrie) PL increased from $3.15 \mathrm{nmol} / \mathrm{L}$ one hour before TCD to $12.84 \mathrm{nmol} / \mathrm{L}$ one hour later, at TCD. Associated with these increases in PL were steep increases in the level of cortisol from $32 \mathrm{nmol} / \mathrm{L}$ (Amie) and $25 \mathrm{nmol} / \mathrm{L}$ (Zandrie) to $347 \mathrm{nmol} / \mathrm{L}$ and 248 nmol/L during the 7 to 9 hours before TCD. These increases in cortisol by 315 and 223 nmol/L were substantially larger than those in the other 23 bitches over the same period 
(mean 33.2, SD $54.6 \mathrm{nmol} / \mathrm{L}$, ranging from a decrease by $76 \mathrm{nmol} / \mathrm{L}$ to a maximum rise by $138 \mathrm{nmol} / \mathrm{L})$.

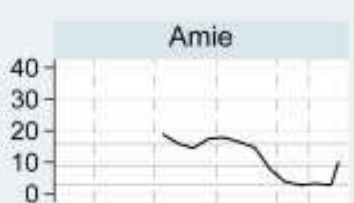

Lady

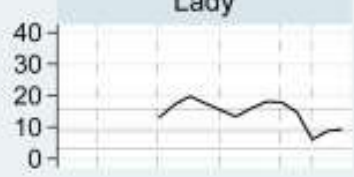

Mocca

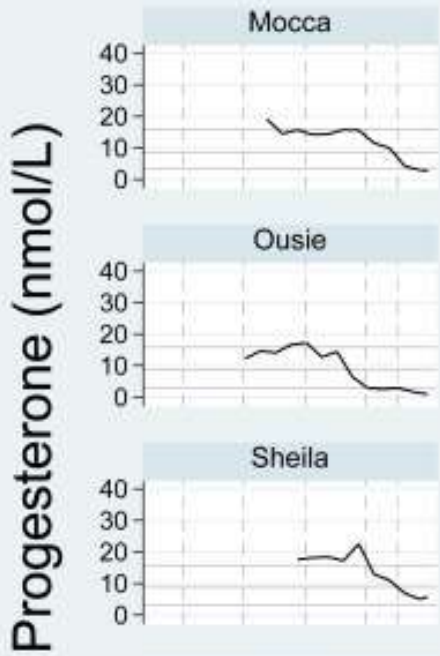

Tinka
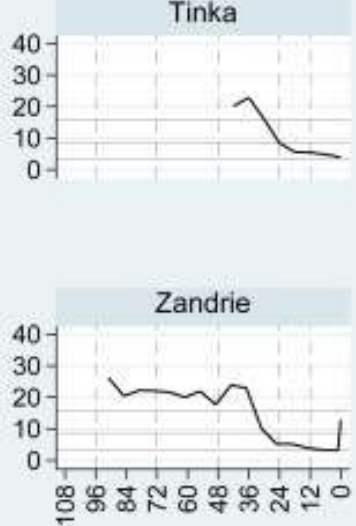

Amy

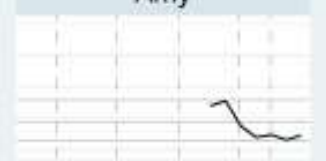

Lallie

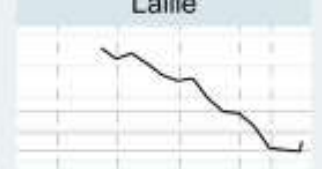

Nala

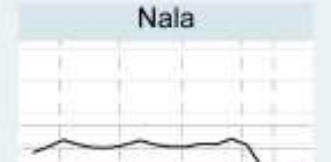

Princess

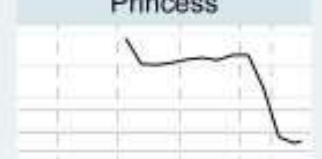

Siska

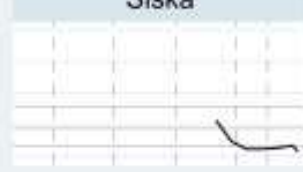

Toska

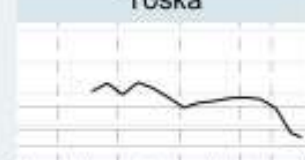

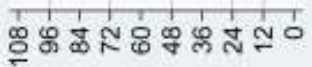

Anja

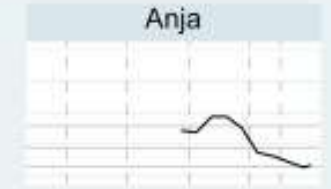

Leelo

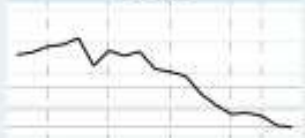

Nanuschka

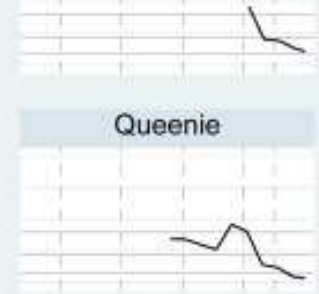

Smartie

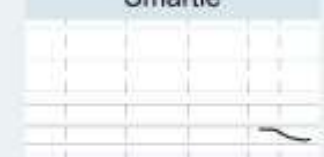

Velvet

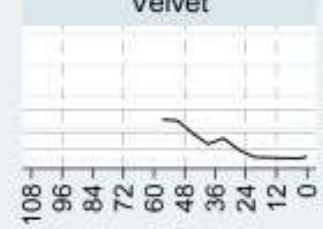

Kira

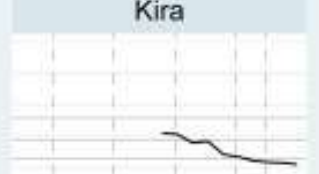

Leyla

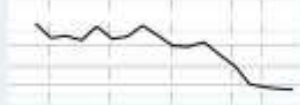

Ole

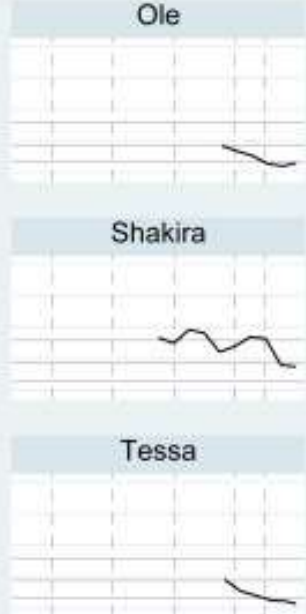

Zahrie

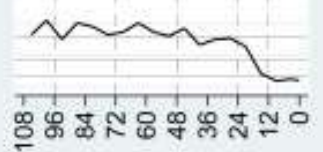

\section{Hours to TCD}

Horizontal reference lines at $3.18,8.7$ and $15.8 \mathrm{nmol} / \mathrm{L}$.

Progesterone levels measured at 0:00, 06:00, 12:00 and 18:00, and once cervical dilatation was first observed.

Figure 1. The level of progesterone in blood plasma of 25 bitches, measured six-hourly during the last few days before the time of cervical dilatation (TCD) 
For the 25 bitches, the median and interquartile range in PL at TCD were 3.43 (1.59-6.1) $\mathrm{nmol} / \mathrm{L}$, with values ranging from $0.95 \mathrm{nmol} / \mathrm{L}$ to $12.84 \mathrm{nmol} / \mathrm{L}$.

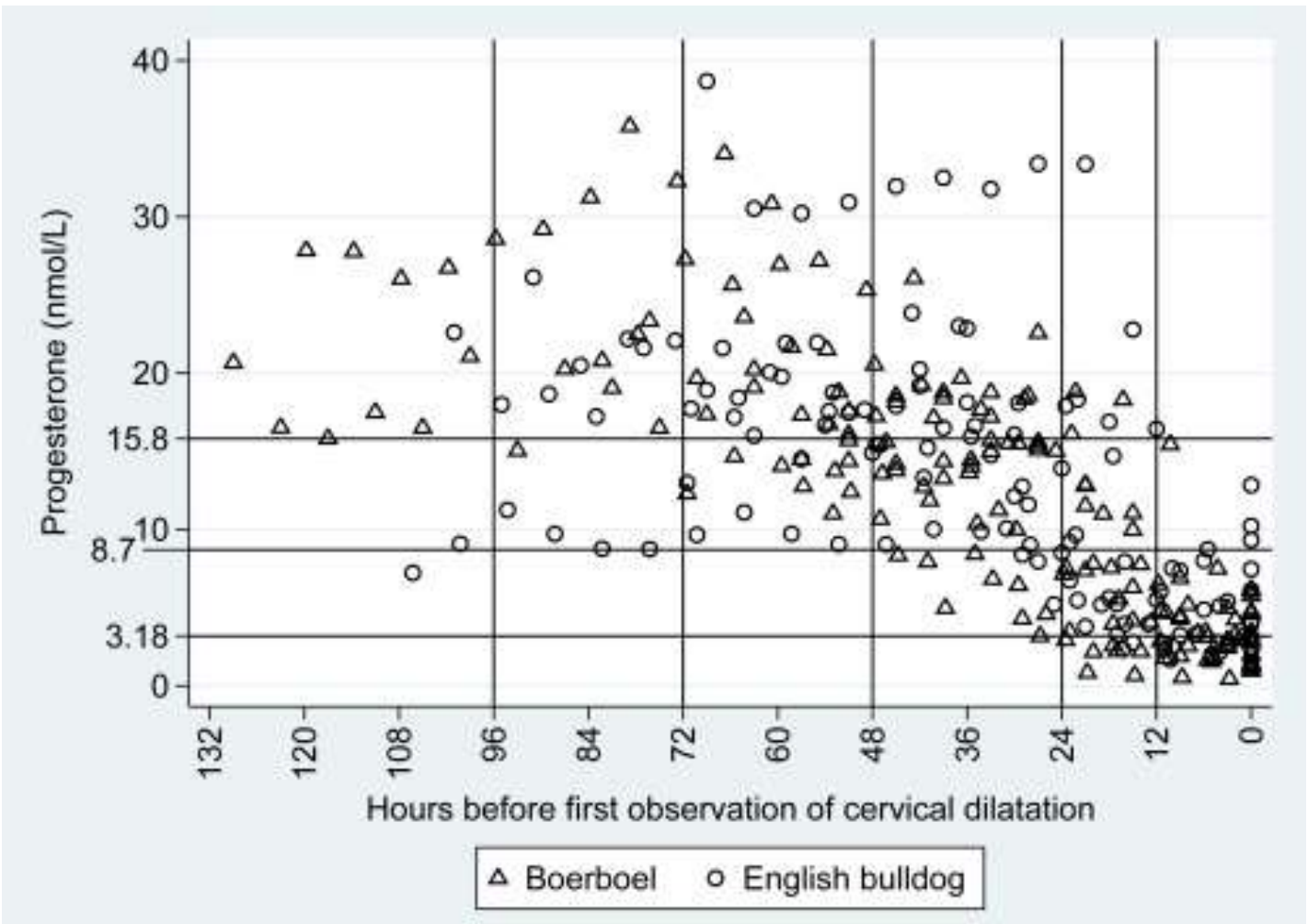

Figure 2.Scatterplot of the 272 progesterone levels prior to the onset of cervical dilatation of 25 bitches, as well as the 25 levels at the time of cervical dilatation (Time zero), with reference lines used to identify possible cross points

\subsubsection{Useful cross points}

Applying the 12-, 24-, 48-, 72- and 96-hours time lines (Figure 2), revealed that PL lines of 3.18-, 8.7- and $15.8 \mathrm{nmol} / \mathrm{L}$ may identify useful cross points.

Table 1 identifies the cross points with few PLs in the top-right quadrant. Nine percent of bitches destined to reach TCD within 24 hours but only two percent destined to do so within 12 hours are expected to have a PL of $15.8 \mathrm{nmol} / \mathrm{L}$ or above. Six percent of bitches destined to reach TCD within 12 hours are expected to have a PL of $8.7 \mathrm{nmol} / \mathrm{L}$ or above. Not reflected in Table 1 is that the FNF for the $12 \mathrm{~h}$ by $3.18 \mathrm{nmol} / \mathrm{L}$ cross point is $52 \%$, implying 
that $52 \%$ of bitches destined to reach TCD within $12 \mathrm{~h}$ will have a PL of $3.18 \mathrm{nmol} / \mathrm{L}$ or above.

Figure 1 shows that PL determination started 96 hours or more before TCD in only four of the 25 bitches and 72 hours or more before in nine. Ninety six hours and 72 hours were therefore not considered as timelines in this study. Figure 1 shows that PL determination started $48 \mathrm{~h}$ or more in $18,24 \mathrm{~h}$ or more in 23 and $12 \mathrm{~h}$ or more in all 25 bitches.

Figure 1 shows that the first PL measured was already below $15.8 \mathrm{nmol} / \mathrm{L}$ in 12 of the 25 bitches and $15.8 \mathrm{nmol} / \mathrm{L}$ was therefore not considered as a PL line identifying a bottom left quadrant that is sparsely populated with PLs. Figure 1 also shows that the first PL measured was below $8.7 \mathrm{nmol} / \mathrm{L}$ in three bitches, whereas the first PL of each bitch was above 3.18 nmol/L. Table 2 identifies the cross points with no or few PLs in their bottom left quadrants. Ninety nine percent of bitches with a PL below $8.7 \mathrm{nmol} / \mathrm{L}$ are expected to reach TCD within 48 hours and all bitches with a PL below $3.18 \mathrm{nmol} / \mathrm{L}$ are expected to do so within 24 hours. Time to cervical dilatation $(\mathrm{P}<0.001)$ but not breed $(\mathrm{P}=0.41)$ or the interaction between them $(\mathrm{P}=0.40)$ affected progesterone levels. Tables 1 and 2 show that breed did not affect the efficacy of the selected cross points as predictors of the time of cervical dilatation $(\mathrm{P}>$ $0.05)$. 
Table 1. Useful cross points by which the progesterone level in blood plasma (PL) may aid in predicting the time of onset of cervical dilatation because few progesterone levels occur in their top right quadrants

\begin{tabular}{|c|c|c|c|c|c|c|c|c|c|c|}
\hline \multirow[b]{2}{*}{ Cross point } & \multicolumn{3}{|c|}{ Bulldogs } & \multicolumn{3}{|c|}{ Boerboels } & \multicolumn{4}{|c|}{ Both breeds } \\
\hline & $\operatorname{FNF}(\%)^{\mathrm{a}}$ & $\mathrm{PLs}^{\mathrm{b}}$ & Bitches & FNF (\%) & PLs & Bitches & FNF (\%) & $95 \% \mathrm{CI}^{\mathrm{c}}$ & PLs & Bitches \\
\hline $24 \mathrm{~h}$ by $15.8 \mathrm{nmol} / \mathrm{L}$ & $13.7^{\mathrm{c}}$ & 44 & 11 & $5.4^{\mathrm{c}}$ & 56 & 14 & 9 & $5-16$ & 100 & 25 \\
\hline $12 \mathrm{~h}$ by $15.8 \mathrm{nmol} / \mathrm{L}$ & $4.5^{\mathrm{d}}$ & 22 & 11 & $0^{\mathrm{d}}$ & 28 & 14 & 2 & $0-10$ & 50 & 25 \\
\hline $12 \mathrm{~h}$ by $8.7 \mathrm{nmol} / \mathrm{L}$ & $9.1^{\mathrm{e}}$ & 22 & 11 & $3.6^{\mathrm{e}}$ & 28 & 14 & 6 & $2-16$ & 50 & 25 \\
\hline
\end{tabular}

${ }^{\mathrm{a}}$ False negative fraction; ${ }^{\mathrm{b}}$ Number of progesterone levels; ${ }^{\mathrm{c}} \mathrm{P}=0.18 ;{ }^{\mathrm{d}} \mathrm{P}=0.44 ;{ }^{\mathrm{e}} \mathrm{P}=0.58$

Table 2. Useful cross points by which the progesterone level in blood plasma may aid in predicting the time of onset of cervical dilatation because few progesterone levels occur in their bottom left quadrants

\begin{tabular}{|c|c|c|c|c|c|c|c|c|c|c|}
\hline \multirow[b]{2}{*}{ Cross point } & \multicolumn{3}{|c|}{ Bulldogs } & \multicolumn{3}{|c|}{ Boerboels } & \multicolumn{4}{|c|}{ Both breeds } \\
\hline & PPV $(\%)^{\mathrm{a}}$ & $\mathrm{PLs}^{\mathrm{b}}$ & Bitches & PPV (\%) & PLs & Bitches & PPV (\%) & $95 \% \mathrm{CI}^{\mathrm{c}}$ & PLs & Bitches \\
\hline $48 \mathrm{~h}$ by $8.7 \mathrm{nmol} / \mathrm{L}$ & $97.3^{\mathrm{c}}$ & 37 & 11 & $100^{\mathrm{c}}$ & 55 & 14 & 99 & $94-100$ & 92 & 25 \\
\hline $24 \mathrm{~h}$ by $8.7 \mathrm{nmol} / \mathrm{L}$ & $89.2^{\mathrm{d}}$ & 37 & 11 & $83.6^{\mathrm{d}}$ & 55 & 14 & 86 & $77-92$ & 92 & 25 \\
\hline $24 \mathrm{~h}$ by $3.18 \mathrm{nmol} / \mathrm{L}$ & $100^{\mathrm{e}}$ & 12 & 6 & $100^{\mathrm{e}}$ & 21 & 10 & 100 & $90-100$ & 33 & 16 \\
\hline
\end{tabular}

${ }^{\mathrm{a}}$ Positive predictive value; ${ }^{\mathrm{b}}$ Number of progesterone levels; ${ }^{\mathrm{c}} \mathrm{P}=0.40 ;{ }^{\mathrm{d}} \mathrm{P}=0.55 ;{ }^{\mathrm{e}} \mathrm{P}=1$ 


\subsubsection{Performance of cross points with low false negative fractions}

Cross point $15.8 \mathrm{nmol} / \mathrm{L}$ by 24 hours Six bitches that were less than $24 \mathrm{~h}$ prior to TCD yielded 9 PLs of $15.8 \mathrm{nmol} / \mathrm{L}$ or above from 12 to $23.5 \mathrm{~h}$ before TCD (mean 19.19, SD 4.04 h). These 9 PLs represent false predictions that TCD would not have occurred within $24 \mathrm{~h}$ in bitches with PLs of $15.8 \mathrm{nmol}$ or above. With these 9 false predictions, TCD occurred $0.5-12$ $\mathrm{h}$ (mean 4.81, SD $4.04 \mathrm{~h}$ ) before the end of the 24-hour period during which TCD was predicted not to have occurred.

Cross point $15.8 \mathrm{nmol} / \mathrm{L}$ by 12 hours A PL of $16.4 \mathrm{nmol} / \mathrm{L}$ occurred in Shakira $12 \mathrm{~h}$ prior to TCD (Figure 1), which constitutes the only false prediction that TCD would not occur within $12 \mathrm{~h}$ in bitches with PLs of $15.8 \mathrm{nmol} / \mathrm{L}$ or above. In Shakira, TCD occurred zero hours before the predicted 12-hour period has lapsed.

Cross point $8.7 \mathrm{nmol} / \mathrm{L}$ by 12 hours A PL of $8.7 \mathrm{nmol} / \mathrm{L}$ or above in three bitches falsely predicted that they would not have reached TCD within 12 hours. They were Shakira with a PL of $16.4 \mathrm{nmol} / \mathrm{L} 12$ hours before TCD, Toska with a PL of $15.4 \mathrm{nmol} / \mathrm{L} 10.3$ hours before TCD and Lady with a PL of $8.7 \mathrm{nmol} / \mathrm{L} 5.5$ hours before TCD). In these bitches TCD occurred zero, 1.7 and $6.5 \mathrm{~h}$ before the end of the 12-hour period during which TCD was predicted to not have occurred.

\subsubsection{Performance of cross points with high positive predictive values}

Cross point 8.7 nmol/L by 48 hours In three bitches (Nala, Ole and Smartie) blood collection started after PL had decreased below $8.7 \mathrm{nmol} / \mathrm{L}$. In only one of these did blood collection start more than 48 hours before TCD (Nala, 106.3 hours before TCD, Figure 1). Among the 22 bitches where blood collection started before PL decreased below $8.7 \mathrm{nmol} / \mathrm{L}$ for the first time, it always decreased below $8.7 \mathrm{nmol} / \mathrm{L}$ less than 48 hours before TCD (Table 3). 
Cross point $3.18 \mathrm{nmol} / \mathrm{L}$ by 24 hours In eight bitches PL failed to decrease below 3.18 nmol/L by TCD. In a ninth (Leelo, Figure 1) the PL measured at TCD was the first to be below $3.18 \mathrm{nmol} / \mathrm{L}$. Table 3 shows that in none of the 16 bitches where PL decreased below $3.18 \mathrm{nmol} / \mathrm{L}$ prior to TCD did it do so more than $24 \mathrm{~h}$ prior to TCD.

Table 3. Interval to the time of cervical dilatation (hours) in bitches where the plasma progesterone level decreased below the threshold while the cervix was still closed

\begin{tabular}{lcccccc}
\hline & Min & $\mathrm{Q}_{1}$ & Median & $\mathrm{Q}_{3}$ & Max & Bitches \\
\hline First decrease below 8.7 nmol/L & 4.3 & 10.9 & 19.0 & 25.3 & 44.8 & 22 \\
First decrease below 3.18 nmol/L & 0.8 & 3.4 & 10.5 & 16.8 & 23.5 & 16 \\
\hline
\end{tabular}

\section{Discussion}

Although cervical dilatation is a reliable and safe indicator of readiness for CS in the bitch, it has no predictive value of the onset of parturition as parturition is by then imminent $[1 ; 33]$. Determining whether the cervix is dilating using a speculum is easy to perform and very reliable but requires some experience. Firstly one must use the correct size speculum for the size of the dog. Secondly one may have to apply suction to remove some mucus from the cranial vagina in order to visualize the cervix and one must have a proper light source.

The interval between mating and parturition in the bitch is highly variable, with a range of 10 days and a large standard deviation of 2.59 days [4]. Events during estrus, such as the first or only day of the LH surge, the day on which PL first exceeds $6 \mathrm{nmol} / \mathrm{L}$ or $16 \mathrm{nmol} / \mathrm{L}$ or the day of onset of cytological diestrum allow for more precise prediction of when parturition is due [34]. In two small studies [14;35] and one somewhat larger study [36], the estimated time of ovulation was successfully used to determine when to perform caesarean section in 
bitches. Often, bitches are not assessed during estrus, leaving the obstetrician with a problem on predicting when parturition is due.

Progesterone level in the bitch has long been shown to decrease in preparturient bitches [1921;37]. This has also been shown in the current study. Given this pattern of decline, a cut-off below which PL would allow prediction that parturition would start within a known interval would be useful. The shorter this predictive interval the shorter the period during which preparturient bitches will have to be observed for parturition and any complications therewith. If the predictive interval is sufficiently short, it may also allow one to safely perform planned obstetric interventions such as a planned caesarean section. Bitches with a PL below $8.7 \mathrm{nmol} / \mathrm{L}$ are expected to have a dilating cervix within 48 hours and those with a PL below $3.18 \mathrm{nmol} / \mathrm{L}$ within 24 hours.

Apart from the value of a PL below the cut-off, a cut-off is also clinically useful if it allows one to confidently predict that a bitch with a PL above the cut-off is unlikely to start showing signs of parturition within a particular predictive interval. A predictive interval of 12 hours or longer is particularly useful as it would allow a clinician to safely conclude that a preparturient bitch may be left without intense observation overnight. Given the limitations of the current study the low false negative fractions reported in the current study suggest that bitches with a PL above $15.8 \mathrm{nmol} / \mathrm{L}$ are highly unlikely to enter parturition as indicated by a dilating cervix within 12 hours. Similarly, bitches with a PL above $8.7 \mathrm{nmol} / \mathrm{L}$ are unlikely to show cervical dilatation within 12 hours. These two findings may be combined to conclude that bitches with a PL above $8.7 \mathrm{nmol} / \mathrm{L}$ are unlikely to start with parturition, as indicated by cervical dilatation, within 12 hours.

From the above follows that a cut-off would be of maximal use if a PL below that cut-off yields a positive predictive interval (time within which the cervix would start dilating) that is 
sufficiently short to be clinically useful whereas a PL above that same cut-off would allow a negative predictive interval (interval within which cervical dilatation is unlikely to start) that is sufficiently long to be clinically useful. The cut-off of $8.7 \mathrm{nmol} / \mathrm{L}$ offers a positive predictive interval of $48 \mathrm{~h}$ while offering the same, sufficiently long negative predictive interval $(12 \mathrm{~h})$ as a cut-off of $15.8 \mathrm{nmol} / \mathrm{L}$. Although the cut-off of $3.18 \mathrm{nmol} / \mathrm{L}$ offers a short positive predictive interval of 24 hours it is unreliable as a criterion by which to predict that TCD would not occur within 12 hours: $52 \%$ of bitches predicted not to reach TCD within 12 hours because their PL is $3.18 \mathrm{nmol}$ or higher will actually do so.

The current study has three limitations. The first limitation is that when deciding on and assessing possible cross points, we interpreted the PLs as if they were random samples from 272 preparturient bitches that were at the time intervals prior to TCD associated with the 272 PLs of the current study, which they were not; they were repeated samples from each of 25 bitches. Nevertheless, the wide spread in PLs at any time before TCD, together with the combined pattern of decline towards TCD shown by the 272 PLs suggest that they may approximate those expected from 272 bitches at the same intervals before TCD as the 272 PLs of the current study. This notion is also supported by the results that the 25 bitches in the current study matched the predictions implied by the cross points quite well—especially with respect to the FNF associated with the $15.8 \mathrm{nmol} / \mathrm{l}$ by $12 \mathrm{~h}$ - and the 8.7 by $12 \mathrm{~h}$ cross points and the PPV associated with the 8.7 by $48 \mathrm{~h}$ - and the 3.18 by $24 \mathrm{~h}$ cross points. We nevertheless suggest caution in generalizing the inference to all bitches.

A second limitation is that we excluded singleton pregnancies. It is suspected that incomplete luteolysis might have a role in the singleton enigma [38;39]. If so, preparturient PL may be of limited use in alerting the veterinary obstetrician to imminent parturition in singleton pregnancies and singletons were therefore removed from the current study. Further research is required as to how best deal with the singleton pregnancy. 
A third limitation of the current study is that only two breeds are represented. It is not known whether the pattern and rate of decline in PL prior to parturition differs among breeds. Although the general pattern of decline in PL caused PL to depend on time to cervical dilatation, it was similar for the two breeds in the current study.

We suspect that the large increase in plasma cortisol levels in Amie and Zandrie during the seven to nine hours prior to cervical dilatation was due to stress associated with the first stage of parturition. Stress is known to induce increased levels of cortisol and progesterone in the blood [40-42] and that this progesterone is derived from the adrenal [40].

Our study concurs with that of Rota et al. (2015) in which they concluded that "Due to a very large individual variation [with respect to the interval between reaching a specific level of progesterone in their serum and parturition], a single progesterone determination has low diagnostic efficacy, although it can represent a useful first screening"[43]. Given the limitations of the current study, its results justifies future research as follows to assess the general applicability of its findings in bitches of a variety of breeds carrying litters larger than one where the time of spontaneous cervical dilatation (TCD) has to be identified to the nearest six hours by means of PL in conjunction with vaginal speculum examination: If the cervix of a bitch in late gestation is still closed her PL is immediately measured. If it is 8.7 $\mathrm{nmol} / \mathrm{L}$ or above, vaginal speculum examinations will be continued 12-hourly-immediately followed by PL determination as long as the cervix is closed - until TCD has occurred or PL has decreased below $8.7 \mathrm{nmol} / \mathrm{L}$. Once PL has decreased below $8.7 \mathrm{nmol} / \mathrm{L}$, no further PLs will be measured but 6-hourly speculum examinations done to identify TCD. (TCD is expected within $48 \mathrm{~h}$ after the first PL occurs that is below $8.7 \mathrm{nmol} / \mathrm{L}$ but $3.18 \mathrm{nmol} / \mathrm{L}$ or higher and within $24 \mathrm{~h}$ if it is below $3.18 \mathrm{nmol} / \mathrm{L}$.) 
Baan et al. (2005) and Levy et al. (2009) showed that elective caesarean section can be done effectively on average 2-2.5 days prior to the expected day of parturition based on the estimated day of ovulation in bitches pretreated with aglepristone. In a small study, Vannucchi et al. (2012) showed that caesarean section may be done effectively about $5 \mathrm{~d}$ before the day on which parturition is expected based on the estimated time of ovulation in bitches pretreated with a corticosteroid. In contrast to these studies, it is not known how long before parturition an elective caesarean section can safely be done in bitches that have not received any pretreatment and where estrus has not been monitored. If an elective caesarean section is contemplated and the safe interval prior to TCD during which it may be done were known, vaginal speculum examination immediately followed by PL determination may be used to estimate the time of readiness for caesarean section: If, for example, it were known (which it is not) that it is safe to perform an elective caesarean section 24 hours prior to TCD, the safety of performing the elective caesarean section 24 hours after the first PL below 8.7 $\mathrm{nmol} / \mathrm{L}$ but equal to or above $3.18 \mathrm{nmol} / \mathrm{L}$ has occurred, provided that another PL 24 hours after the first below $8.7 \mathrm{nmol} / \mathrm{L}$ shows a distinctly lower level. If it were safe to perform an elective caesarean section 24 hours prior to TCD, it is justified to investigate the safety of performing the caesarean section once a PL below $3.18 \mathrm{nmol} / \mathrm{L}$ occurs.

The attempt made in the current study to determine the precision with which PL in the preparturient bitch is able to predict TCD is important in the context of planning when to perform elective caesarean sections. This is because the risk associated with poor precision could lead to performing CSs too early or too late with catastrophic consequences for the fetuses and possible legal actions if, retrospectively, intervention or lack thereof is claimed to have reduced puppy survival. Despite the identification in the current study of cross points with time lines below $48 \mathrm{~h}$ that are associated with high PPVs, further studies are required to establish whether it is safe to routinely perform CSs based on the PL having decreased below 
the level suggested by the PL-line of the critical cross point. These results would allow the veterinary obstetrician to make prompt decisions in the management of parturition.

\section{Conclusions}

A cut-off in PL of $15.8 \mathrm{nmol} / \mathrm{L}$ is clinically useful as a single $\mathrm{PL}$ above $15.8 \mathrm{nmol} / \mathrm{L}$ in a bitch with a closed cervix indicates that she is unlikely to start with parturition (cervical dilatation) within 12 hours. A cut-off in PL of $8.7 \mathrm{nmol} / \mathrm{L}$ is clinically useful as a single PL below $8.7 \mathrm{nmol} / \mathrm{L}$ in a bitch with a closed cervix indicates that she is likely to start with parturition (cervical dilatation) within 48 hours and a PL above $8.7 \mathrm{nmol} / \mathrm{L}$ that she is unlikely to do so within 12 hours. Further, a cut-off of $3.18 \mathrm{nmol} / \mathrm{L}$ is also clinically useful because a single PL below $3.18 \mathrm{nmol} / \mathrm{L}$ in a bitch with a closed cervix indicates that she is likely to start with parturition (cervical dilatation) within 24 hours.

\section{Author contributions}

J O Nöthling was the supervisor of the scientific protocol, performed the statistical analyses and assisted in drafting the protocol. K.G.M. De Cramer was the main person involved in experimental work and wrote the protocol. The authors jointly wrote the manuscript.

\section{Conflicts of interest}

None of the authors of this paper has a financial or personal relationship with other people or organizations that could inappropriately influence or bias the content of this manuscript.

\section{References}

[1] Smith FO. Challenges in small animal parturition--timing elective and emergency cesarian sections. Theriogenology 2007;68:348-53.

[2] Linde-Forsberg C, Eneroth A. Abnormalities in pregnancy, parturition and the periparturient period; in Ettinger SJ, Feldman EC (eds): Textbook of Veterinary Internal Medicine. Philadelphia, Saunders, P.A., 2000, p 1655-77. 
[3] Concannon P, Whaley S, Lein D, Wissler R. Canine gestation length: variation related to time of mating and fertile life of sperm. American Journal of Veterinary Research 1983;44:1819-21.

[4] Holst PA, Phemister RD. Onset of diestrus in the beagle bitch: definition and significance. American Journal of Veterinary Research 1974;35:401-6.

[5] Tsutsui T, Hori T, Kirihara N, Kawakami E, Concannon PW. Relation between mating or ovulation and the duration of gestation in dogs. Theriogenology 2006;66:1706-8.

[6] Shimatsu Y, Yuzawa H, Aruga K, Nakura M. Effect of time for mating and gestation length on reproductive efficiency in dogs. Reprod Domest Anim 2007;42:664-5.

[7] Son CH, Jeong KA, Kim JH, Park IC, Kim SH, Lee CS. Establishment of the Prediction Table of Parturition Day with Ultrasonography in Small Pet Dogs. Journal of Veterinary Medical Science 2001;63:715-21.

[8] Luvoni GC, Beccaglia M. The prediction of parturition date in canine pregnancy. Reprod Domest Anim 2006;41:27-32.

[9] Kutzler MA, Yeager AE, Mohammed HO, Meyers-Wallen VN. Accuracy of canine parturition date prediction using fetal measurements obtained by ultrasonography. Theriogenology 2003;60:1309-17.

[10] Batista M, Moreno C, Vilar J, Golding M, Brito C, Santana M et al. Neonatal viability evaluation by Apgar score in puppies delivered by cesarean section in two brachycephalic breeds (English and French bulldog). Animal Reproduction Science 2014;146:218-26.

[11] Concannon PW, Powers ME, Holder W, Hansel W. Pregnancy and parturition in the bitch. Biol Reprod 1977;16:517-26.

[12] Tsutsui T, Murata Y. Variations in body temperature in the late stage of pregnancy and parturition in bitches. Nippon juigaku zasshi The Japanese journal of veterinary science 1982;44:571-6.

[13] Veronesi MC, Battocchio M, Marinelli L, Faustini M, Kindahl H, Cairoli F. Correlations among body temperature, plasma progesterone, cortisol and prostaglandin F2alpha of the periparturient bitch. J Vet Med A Physiol Pathol Clin Med 2002;49:264-8.

[14] Baan M, Taverne MA, Kooistra HS, de Gier J., Dieleman SJ, Okkens AC. Induction of parturition in the bitch with the progesterone-receptor blocker aglepristone. Theriogenology 15-4-2005;63:1958-72.

[15] Corrada Y, García P, De La Sota PE, Huzman M, Landoni MF, Gobello C. Decrease of body temperature after aglepristone treatment in bitches. Animal Reproduction Science 2005;87:295-9.

[16] Long D, Mezza R, Krakowka S. Signs of impending parturition in the laboratory bitch. Lab Anim Sci 1978;28:178-81.

[17] Linde-Forsberg C, Eneroth A. Parturition. BSAVA Manual of Small Animal Reproduction and Neonatology 1998;127-42.

[18] Johnston SD, Kustritz MVR, Olson PNS. Canine and Feline Theriogenology. W B Saunders, 2001.

[19] Concannon PW, Hansel W, Visek WJ. The ovarian cycle of the bitch: plasma estrogen, LH and progesterone. Biology of Reproduction 1975;13:112-21.

[20] England GC, Verstegen JP. Prediction of parturition in the bitch using semiquantitative ELISA measurement of plasma progesterone concentration. Vet Rec 1611-1996;139:496-7. 
[21] Onclin K, Verstegen JP. Secretion patterns of plasma prolactin and progesterone in pregnant compared with nonpregnant dioestrous beagle bitches. J Reprod Fertil Suppl 1997;51:203-8.

[22] Srikandakumar A, Ingraham RH, Ellsworth M, Archbald LF, Liao A, Godke RA. Comparison of a solid-phase, no-extraction radioimmunoassay for progesterone with an extraction assay for monitoring luteal function in the mare, bitch, and cow. Theriogenology 1986;26:779-93.

[23] Reimers TJ, Lamb SV, Bartlett SA, Matamoros RA, Cowan RG, Engle JS. Effects of hemolysis and storage on quantification of hormones in blood samples from dogs, cattle, and horses. American Journal of Veterinary Research 1991;52:1075-80.

[24] Gerstenberg C, Nöthling JO. The effects of metergoline combined with PGF2alpha treatment on luteal function and gestation in pregnant bitches. Theriogenology 1995;44:649-59.

[25] Okkens AC, Teunissen JM, Van Osch W, Van Den Brom WE, Dieleman SJ, Kooistra HS. Influence of litter size and breed on the duration of gestation in dogs. Journal of reproduction and fertility Supplement 2001;57:193-7.

[26] Kutzler MA, Mohammed HO, Lamb SV, Meyers-Wallen VN. Accuracy of canine parturition date prediction from the initial rise in preovulatory progesterone concentration. Theriogenology 2003;60:1187-96.

[27] Luz MR, Bertan CM, Binelli M, Lopes MD. Plasma concentrations of 13,14-dihydro15-keto prostaglandin $\mathrm{F}_{2}$-alpha (PGFM), progesterone and estradiol in pregnant and nonpregnant diestrus cross-bred bitches. Theriogenology 2006;66:1436-41.

[28] Steckler D, Nöthling JO, Harper C. Prediction of the optimal time for insemination using frozen-thawed semen in a multi-sire insemination trial in bitches. Animal Reproduction Science 30-11-2013;142:191-7.

[29] Kemppainen RJ, Thompson FN, Lorenz MD. Use of a low dose synthetic ACTH challenge test in normal and prednisone-treated dogs. Research in Veterinary Science 1983;35:240-2.

[30] Watson ADJ, Church DB, Emslie DR. Plasma cortisol concentrations in dogs given cortisone or placebo by mouth. Research in Veterinary Science 1993;55:379-81.

[31] Russell NJ, Foster S, Clark P, Robertson ID, Lewis D, Irwin PJ. Comparison of radioimmunoassay and chemiluminescent assay methods to estimate canine blood cortisol concentrations. Austr Vet J 2007;85:487-94.

[32] Dohoo I, Martin W, Stryhn H. Veterinary Epidemiologic Research, ed 2nd. Manitoba Canada, VER Inc, 2009.

[33] De Cramer KGM, Joubert KE, Nöthling JO. Puppy survival and vigor associated with the use of low dose medetomidine premedication, propofol induction and maintenance of anesthesia using sevoflurane gas-inhalation for cesarean section in the bitch. Theriogenology 2017;96:10-5.

[34] De Cramer KGM, Nöthling JO. The precision of peri-oestrous predictors of the date of onset of parturition in the bitch. Theriogenology 2017;96:153-7.

[35] Vannucchi CI, Regazzi FM, Barbosa MMM, Silva L, Veiga G, Lúcio CF et al. Cortisol Profile and Clinical Evaluation of Canine Neonates Exposed Antenatally to Maternal Corticosteroid Treatment. Reprod Domest Anim 2012;47:173-6.

[36] Levy X, Fontaine E, Segalini V, Fontbonne A. Elective caesarean operation in the bitch using aglepristone before the pre-partum decline in peripheral progesterone concentration. Reprod Domest Anim 2009;44 Suppl 2:182-4.

[37] Concannon PW, Isaman L, Frank DA, Michel FJ, Currie WB. Elevated concentration of 13,14-dihydro-15-keto-prostaglandin F-2 alpha in maternal plasma during 
prepartum luteolysis and parturition in dogs (Canis familiaris). Journal of Reproduction and Fertility 1988;84:71-7.

[38] Lopate C. Estimation of gestational age and assessment of canine fetal maturation using radiology and ultrasonography: a review. Theriogenology 2008;70:397-402.

[39] Johnson CA. High-risk pregnancy and hypoluteoidism in the bitch. Theriogenology 2008;70:1424-30.

[40] Bruce NW, Willcox DL, Meyer GT, Waddell BJ. Effects of handling, anaesthesia, ovariectomy and adrenalectomy on serial measurements of plasma progesterone in 16-day pregnant rats. Journal of Endocrinology 1-2-1984;100:189-93.

[41] Elman I, Breier A. Effects of acute metabolic stress on plasma progesterone and testosterone in male subjects: Relationship to pituitary-adrenocortical axis activation. Life Sciences 1997;61:1705-12.

[42] Romeo RD, Lee SJ, McEwen BS. Differential Stress Reactivity in Intact and Ovariectomized Prepubertal and Adult Female Rats. Neuroendocrinology 2004;80:387-93.

[43] Rota A, Charles C, Starvaggi Cucuzza A, Pregel P. Diagnostic Efficacy of a Single Progesterone Determination to Assess Full-Term Pregnancy in the Bitch. Reprod Domest Anim 2015;50:1028-31. 